\title{
Study on volcanic reservoir characteristics of Yingcheng Formation in Xudong area of Xujiaweizi fault depression
}

\author{
WANG Jial ${ }^{l}$ ZHOU Yue \\ ${ }^{1}$ Exploration and Development Research Institute of Daqing Oil Field Co. L td, Daqing City, Heilongjiang Province, 163712,China
}

\begin{abstract}
Types of deep reservoir rich in $Y$ ingcheng formation of $X$ udong area in $X$ ujiaweizi fault depression, the study of volcanic rocks of $Y$ ingcheng formation in the main, using the date of core, logging, oil test, from lithology, lithofacies and physical properties to study volcanic reservoir characteristics. The main lithology of volcanic reservoir in $Y$ ingcheng formation of $X$ udong area include rhyolite, rhyolitic tuff, rhyolitic tuff fused, rhyolitic breccia and rhyolitic tuff breccia. In accordance with lithology combination of features, volcanic facies can be divided into volcanic explosive facies, volcanic effusive facies and volcanic sedimentary facies. The main types of porosity have air vent of primary pore, remnants pores of air vent filled after, cracks, micro-cracks and feldspar corrosion hole of secondary porosity, volcanic ash corrosion hole, micro-pore produced by rhyolitic glass from glass off in spherules rhyolite, quartz crystal chip corrosion hole, and so on. Through studying the ratio of reservoir and formation for a single well, the frequency distribution of reservoir thickness, production capacity situation and pool-forming regularity, X udong area can be divided into three reservoir development zone, so we will find out the most favorable reservoir development zone, then it can play a guiding role for the next step of the exploration deployment.
\end{abstract}

\section{Preface}

Xudong area is located in the eastern slope zone of Xujiaweizi fault depression in the north of Songliao basin. Its deep reservoir types are relatively rich. There are several types of reservoirs in different layers, such as dense sandstone, glutenite, volcanic rock, bedrock weathering crust, etc. in the depression area, glutenite and volcanic rock are the most important reservoirs. Based on the data of core, well logging and oil testing, the characteristics of volcanic reservoir in this area are studied from the aspects of lithology, lithofacies and physical properties, and the distribution range of favorable reservoirs in Xudong area is determined on the plane. The results play a guiding role in the further exploration and development of volcanic gas reservoirs in this area.

\section{Lithologic characteristics of reservoir}

On the basis of systematic observation of volcanic rock core, identification of thin section by polarizing microscope and analysis of volcanic rock composition (according to the classification and nomenclature scheme of igneous rocks of the International Union of Geosciences, 1989), the types of volcanic rocks are determined. For non coring section, core calibration is applied, and advanced logging technologies such as ECs and FMIS are used to establish lithologic identification method to comprehensively identify the lithology of volcanic rocks.
The lithology and thickness of volcanic reservoirs in 25 wells drilled into Yingcheng Formation in Xudong area are analyzed. The results show that the main lithology of volcanic reservoirs in Xudong area is acidic volcanic rocks, that is, acid rocks account for $92.9 \%$, intermediate acid rocks account for $0.4 \%$, neutral rocks account for $0.6 \%$, and sedimentary tuffs account for $6.1 \%$.

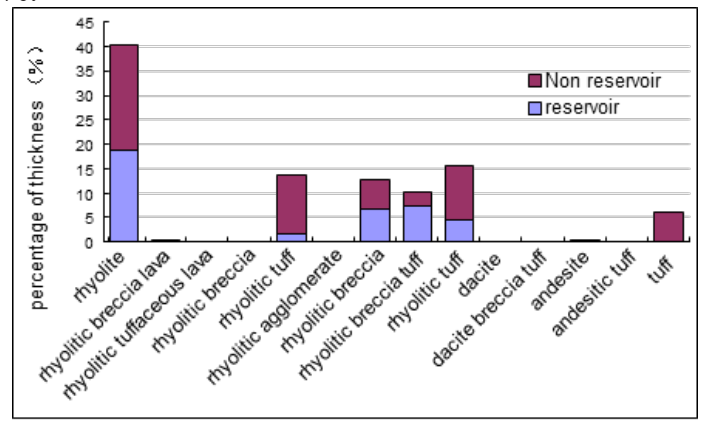

Fig. 1. Reservoir thickness compared with non-reservoir thickness of different volcanic lithology in Yingcheng formation of Xudong area

The main lithology is rhyolite, rhyolitic tuff and rhyolitic fusion Tuff, rhyolitic breccia and rhyolitic breccia tuff accountfor $40.1 \%, 15.6 \%, 13.6 \%, 12.7 \%$ and $10.2 \%$ of the total accumulated thickness of volcanic rocks, respectively. The sequence of reservoir development proportion in the five main lithology is as follows (Fig. 1): rhyolitic breccia tuff $71.9 \%$, rhyolitic breccia $53.7 \%$, rhyolite $46.7 \%$, rhyolitic tuff $29.5 \%$ and

\footnotetext{
* Corresponding author: dqzhouyue@ petrochina.com.cn
} 
rhyolitic fused tuff $11.3 \%$. Combined with the thickness of volcanic rocks and the proportion of reservoir development, it can be seen that rhyolite, rhyolitic breccia tuff, rhyolitic tuff, rhyolitic tuff and rhyolitic fused tuff are favorable reservoirs in Xudong area, and the reservoirs account for $18.7 \%, 7.4 \%, 6.8 \%, 4.6 \%$ and $1.5 \%$ of the total thickness of volcanic rocks respectively. Sedimentary tuff belongs to non reservoir and has no reservoir development.

\section{Lithofacies characteristics of reservoir}

According to the analysis of core, well logging and seismic data, the volcanic rocks in Xudong area can be divided into volcanic eruption facies, volcanic overflow facies and volcanic sedimentary facies according to lithologic association characteristics. Horizontally, the eruptive facies near the crater and the far crater overlapped with the overflow facies, while the volcanic sedimentary facies were mainly distributed in the Northeast; generally speaking, the eruptive facies and overflow facies overlapped each other in general (Fig. 2).

Volcanic eruptive facies can be formed in different stages of volcanism, but it is most developed in the early stage and at the peak of eruption. It is mainly composed of pyroclastic materials and forms clastic cone near the crater with massive structure. Pyroclastic materials fall from the air and accumulate into pyroclastic rocks, or molten pyroclastic rocks formed by hot debris flow, or agglomerates and breccias splashed by volcanic tearing debris. Volcanic agglomerates and volcanic breccias are located in the crater near the crater, and the plane distribution is mostly circular, elliptical or fan-shaped. This facies is the most developed in this area, and can be generally divided into three subfacies: thermal clastic flow subfacies, thermal base wave subfacies and air fall subfacies. The marker rocks of thermal clastic flow subfacies are fused tuff, those of thermal wave subfacies are crystalline tuff, and those of empty subfacies are agglomerate and breccia.

The volcanic overflow facies is formed in various periods of volcanic eruption, but it mainly appears after strong eruption. The magma is ejected from the crater to form the surface overflowing rock cover or linear flow rock flow. The top, bottom or front edge of the lava flow forms pore like lava, breccia lava, etc., with pore, almond and rhyolite structure. Magma eruption is the main volcano, forming shield volcanic rock mass. The overflow phase is generally located near the crater and the transition zone. The thickness of the acid lava is several meters to tens of meters, and in rare cases it can reach hundreds of meters. The overflow facies are generally located on the flank of the volcanic cone or near the crater. The characteristics of seismic facies are wedge-shaped structure, medium weak amplitude, relatively continuous reflection and low frequency. Due to the limitation of seismic resolution, it is difficult to distinguish the upper, middle and lower subfacies of overflow facies thin-layer rhyolite.
Volcanic sedimentary facies is volcanic sedimentary facies, in which volcanic ash, volcanic gravel and clastic rocks are transported by water to the normal sediments in the edge area, or directly fall into the sedimentary water body. The volcanic sedimentary facies is mainly composed of pyroclastic rocks, and other terrigenous clastic materials are added to form volcanic sedimentary rocks. It can be formed in different stages of volcanism, mostly in the far end of volcanic rocks. The main facies belt types in the low-lying areas between the volcanic cones are limited to the volcanoes and volcanic rocks, and the diagenesis is due to compaction. It has massive structure and bedding structure. The subfacies are mainly tuffaceous sedimentary rocks and tuff. Seismic facies characteristics of volcanic sedimentary facies: it is located in the volcanic marginal area outward from the volcanic transition area. Generally, the original tectonic position is relatively low. The seismic reflection characteristics are medium strong amplitude, relatively continuous continuous reflection and parallel structure. This kind of lithofacies stratum has no reservoir capacity at the depth of $3000 \mathrm{~m}$, and can be a good cap rock.

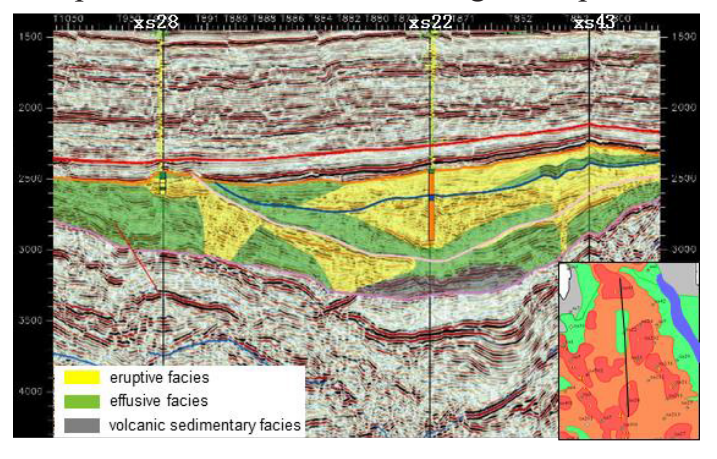

Fig. 2. Typical seismic section analysis of volcanic lithofacies in Yingcheng formation of Xudong area

\section{Reservoir physical characteristics}

According to the genesis and structure, the volcanic reservoir space in Xudong area can be divided into pore, residual pore after pore filling, inner pore in almond, micropore produced by devitrification of rhyolite glass in spherulite rhyolite, feldspar dissolution pore, volcanic ash dissolution pore, carbonate dissolution pore, quartz chip dissolution pore, intergranular pore, shrinkage crack around spherulite, fracture and micro fracture The main pore types are pores of primary pores, residual pores after pore filling, fractures and microfractures, feldspar dissolution pores of secondary pores, volcanic ash dissolution pores, micropores produced by the devitrification of rhyolitic glass in spherulite rhyolites, and dissolution pores of quartz crystal chips (Fig. 3). The above types of reservoir spaces do not exist alone, but appear in a certain combination. There is a close relationship between reservoir space and reservoir rock types. Different rock types have different types of reservoir space combinations. 


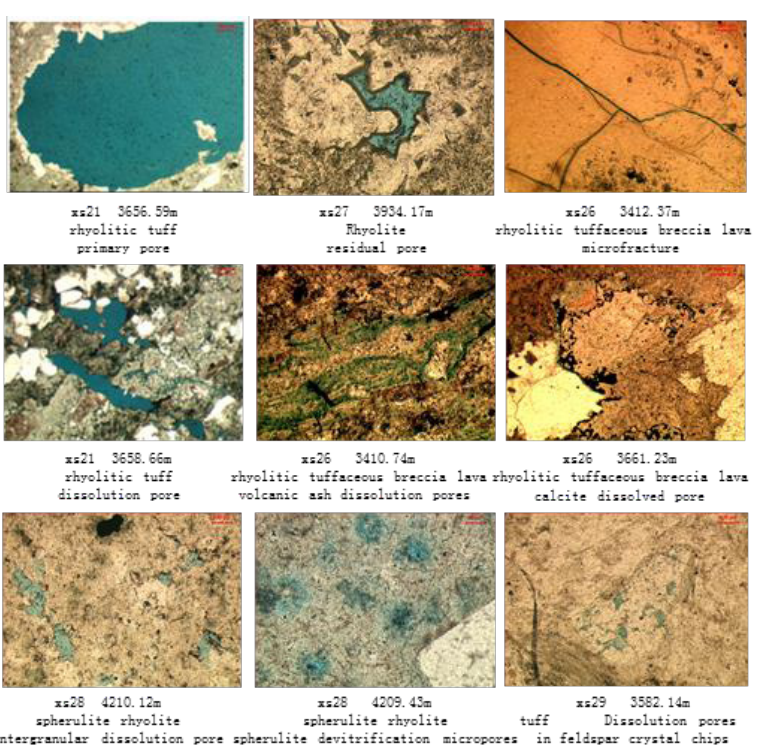

Fig. 3. Pore type of volcanic rock in Yingcheng formation of Xudong area

\section{Plane distribution characteristics of volcanic reservoir in Yingcheng Formation}

The 25 Wells drilled into the volcanic strata of Yingcheng Formation in Xudong area were counted as layers and thickness distribution frequencies of volcanic rocks in single Wells. The results showed that the distribution frequencies of volcanic rock thickness in Xudong area were divided into three types (Fig. 4):

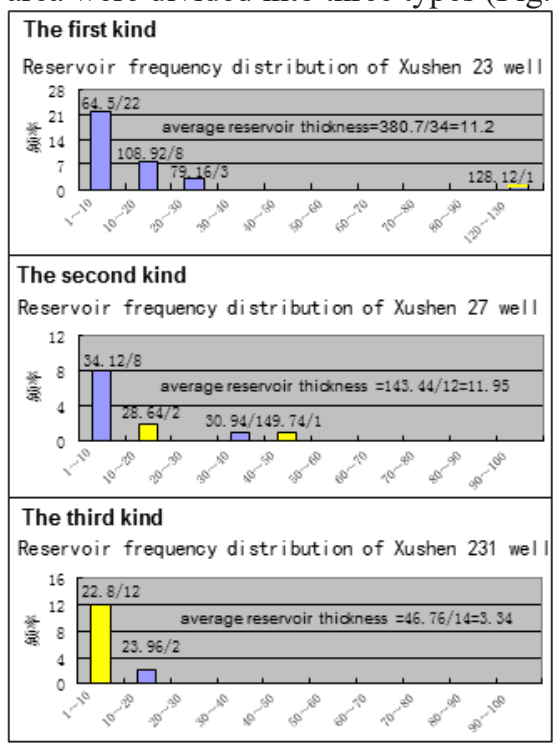

Fig. 4. Classification of frequency distribution of olcanic reservoir thickness in Yingcheng formation of Xudong area

The first type: the maximum thickness of single reservoir layer is more than $70 \mathrm{~m}$, there are 12 wells and 3 industrial gas wells (xs21, xs23 and xs28);

The second type is that the maximum thickness of single layer is less than $70 \mathrm{~m}$ and the thickness of single layer is less than $10 \mathrm{~m}>6$ layers, including 5 wells and 2 industrial gas wells (xs27 and xs213);

The third type: the thickness of single reservoir layer is less than $10 \mathrm{~m}$, there are 8 wells in total, and 1 industrial gas flow well (xs231).

According to the statistics of volcanic reservoir to reservoir ratio of these wells (Fig. 5), the larger the reservoir to reservoir ratio is, the less favorable it is to gas accumulation.

According to single well reservoir to reservoir ratio, reservoir thickness frequency distribution, productivity and reservoir forming law, Xudong area is divided into three reservoir development zones (Table 1, Fig. 6).

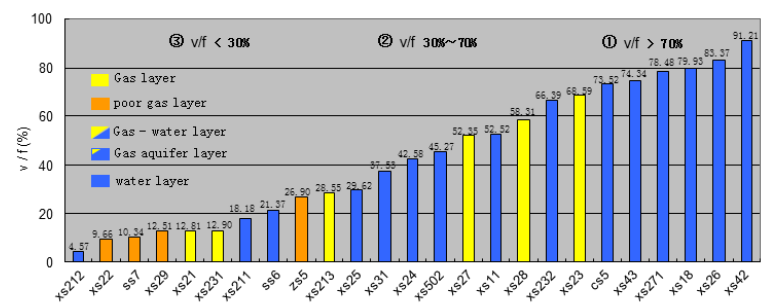

Fig. 5. Distribution of ratio of volcanic reservoir and formation $(\mathrm{v} / \mathrm{f})$ in Yingcheng formation of Xudong area

Table 1. Volcanic reservoir characteristics of the development one in Yingcheng formation of Xudong area

\begin{tabular}{|c|c|c|c|}
\hline $\begin{array}{l}\text { Classif } \\
\text { ication }\end{array}$ & $\mathbf{v} / \mathbf{f}$ & \begin{tabular}{|c|}
$\begin{array}{c}\text { Vertical distribution } \\
\text { characteristics of } \\
\text { reservoir }\end{array}$ \\
\end{tabular} & Characteristic \\
\hline I & lower-low & \begin{tabular}{|c|} 
Continuous \\
distribution of large \\
longitudinal sets
\end{tabular} & $\begin{array}{l}\text { Good reservoir forming } \\
\text { conditions, high yield }\end{array}$ \\
\hline $\mathrm{II}_{1}$ & low & $\begin{array}{c}\text { The continuity of } \\
\text { longitudinal } \\
\text { distribution is poor }\end{array}$ & $\begin{array}{c}\text { Reservoir physical } \\
\text { properties play a decisive } \\
\text { role }\end{array}$ \\
\hline $\mathrm{II}_{2}$ & lower-low & $\begin{array}{l}\text { The continuity of } \\
\text { longitudinal } \\
\text { distribution is poor }\end{array}$ & $\begin{array}{l}\text { North: the volcanic rocks } \\
\text { are thick with poor physical } \\
\text { properties } \\
\text { South: good physical } \\
\text { properties and trap } \\
\text { effectiveness are the main } \\
\text { controlling factors }\end{array}$ \\
\hline $\mathrm{III}_{1}$ & high & $\begin{array}{l}\text { The continuity of } \\
\text { longitudinal } \\
\text { distribution is poor }\end{array}$ & $\begin{array}{c}\text { North: near source, } \\
\text { discontinuous reservoir } \\
\text { distribution and tectonic } \\
\text { activity play a decisive role } \\
\text { in gas reservoir } \\
\text { West: it is far away from the } \\
\text { hydrocarbon generation } \\
\text { center, and the reservoir } \\
\text { physical properties are poor }\end{array}$ \\
\hline $\mathrm{III}_{2}$ & high-lower & $\begin{array}{l}\text { Continuous } \\
\text { distribution of large } \\
\text { longitudinal sets }\end{array}$ & $\begin{array}{l}\text { Southeast: it is far away } \\
\text { from the hydrocarbon } \\
\text { generation center, the } \\
\text { reservoir has good physical } \\
\text { properties, and no effective } \\
\text { trap has been formed }\end{array}$ \\
\hline
\end{tabular}

\section{Conclusion and Cognition}

1. Based on the comprehensive study of the lithology, lithofacies and physical properties of the volcanic rocks of Yingcheng Formation in Xudong area, it is considered that the explosive facies and overflow facies located in the crater near the crater are the favorable facies areas 
for the development of volcanic reservoir; among them, the lava tuff belonging to the pyroclastic flow subfacies of the explosive phase and the rhyolite belonging to the overflow phase are the favorable lithology for the development of the volcanic reservoir.

2. The pore types of volcanic rocks in Xudong area are mainly pores of primary pores, residual pores after filling pores, fractures and micro fractures, feldspar dissolution pores, volcanic ash dissolution pores of secondary pores, micropores produced by the devitrification of rhyolitic glass in spherulite rhyolites, and dissolution pores of quartz crystal chips.

3. Through the analysis and research of single well reservoir to ground ratio, reservoir thickness frequency distribution, productivity and reservoir forming law, the volcanic reservoir development zone in Xudong area is divided, and the most favorable reservoir development zone (type I area) is found out, which is also the area where natural gas is most easy to accumulate, which plays a guiding role for the next exploration deployment. Class I area is located in the main hydrocarbon generation sag, with a large set of reservoirs distributed vertically with good physical properties, and industrial gas flow is obtained from well xs28; the structural position in the south is relatively high, with local reservoir forming, and the structural position in the north is low, which is basically below $-3900 \mathrm{~m}$. According to the situation revealed by the drilled xs22 well, the thickness of volcanic rock is large and the physical property of reservoir is poor, and the deep fault connecting the lower hydrocarbon source rock is not developed It is favorable for natural gas to accumulate from hydrocarbon generating center to this area.

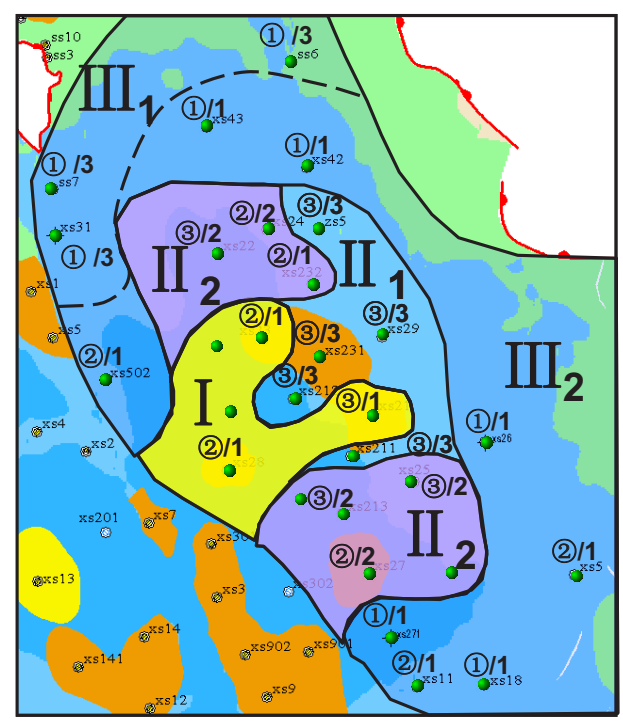

Fig. 6. Distribution of volcanic reservoir development zone in Yingcheng formation of Xudong area

\section{References}

1. Wang Cheng 2014 Pore evolution of volcanic reservoir in Xujiaweizi fault depression (Chinese: Petroleum Geology \& Oilfield Development in Daqing)33 (2): pp $1 \sim 5$
2. Huang Lei 2015 Lithology characteristics and identification methods of volcanic rock in Y ing-I block (Chinese: Petrochemical Industry Technology) (5): pp 211, 233

3. W ang W enguang, Zheng $M$ in, Lu Shuangfang etc. $2015 \mathrm{M}$ ain controlling factors and favorable area prediction of gas reservior of deep volcanic rock in $X$ ujiaweizi fault depression (Chinese: Journal of N ortheast Petroleum University)39 (4): pp $45 \sim 53$

4. Ren Shuaishuai, Zhu Huanlai, Wei Huabin 2018 The Reservoir Characteristics of Deep Volcanic Rock in Xujiaweizi Fault Depression (Chinese: China's Manganese Industry) 36 (6): pp 142 145

5. Dai Lishi 2018 Analysis on lithology of volcanic rocks and physical elastic parameters of reservoir rocks in $Y$ ingcheng Formation of $X$ ujiaweizi fault depression (Chinese: Oil Geophysical Prospecting)53 (1): pp $122 \sim 128$

6. Wu Xiaohu 2019 Petroleum geological characteristics of $Y$ ingcheng Formation in Xujiaweizi fault depression, northern Songliao Basin (Chinese: West-china Exploration Engineering) (6): pp $79 \sim 81$ 